\title{
Observations on the sodium and potassium content of mucus from the large intestine
}

\author{
C. W. CRANE \\ From the Wellcome Research Wing, Department of Medicine, \\ Queen Elizabeth Hospital, University of Birmingham
}

EDITORIAL SYNOPSIS These studies support the view that mucus from the large intestine may contain high concentrations of potassium and demonstrate the ease with which this electrolyte may be removed. Any intestinal condition which prevents adequate degradation or inspissation of mucus will facilitate potassium loss.

Potassium is sometimes depleted in diseases of the intestine in which diarrhoea is a prominent symptom, such as idiopathic steatorrhoea (Lubran and McAllen, 1951) and ulcerative colitis (Posey and Bargen, 1950). Occasionally abnormal quantities of mucus are present in the stools in these conditions. It may occur in patients with villous tumours of the large bowel and is then almost always associated with chronic watery diarrhoea and excessive loss of mucus (Southwood, 1962). In most reports of this complication, sodium depletion and dehydration accompany the hypokalaemia. The stools and watery mucus, in some cases exceeding several litres daily, contain 103 to $158 \mathrm{mEq}$. of sodium and 15 to $80 \mathrm{mEq}$. of potassium per litre (Shnitka, Friedman, Kidd, and MacKenzie, 1961). Southwood (1962) and Duthie and Atwell (1963) drew attention to wide variations in the concentrations of potassium encountered in rectal discharges containing mucus, in contrast to a narrower range for sodium. Roy and Ellis (1959) and Cooling and Marrack (1957) considered that the villous tumours actively secrete potassium, but Shnitka et al. (1961) and Rowe (1964) regarded the excessive loss from the surface of the tumours of mucus, rich in both sodium and potassium, sufficient to account for the electrolyte depletion. The study of mucus from the large bowel is hampered in many instances by difficulties in freeing samples from faeces or blood, while owing to dilution, the electrolyte concentrations found in material recovered from the rectal discharges of patients with villous tumours may not represent those present at the time of secretion.

A report by Little (1964) that mucoid fluid obtained from a colostomy above an annular carcinoma of the colon contained $140 \mathrm{mEq}$. of potassium per litre, indicated that fresh mucus from the large bowel might contain amounts of potassium in excess of those previously reported. A potassium content of $93 \mathrm{mEq}$. per litre in a sample of mucus obtained at operation in this hospital from the surface of a small carcinoma in the rectum of an elderly male patient lent some support to this view.

An opportunity to make a more thorough study of colonic mucus free of faeces and blood arose during the investigation of a patient with a partial volvulus of the sigmoid colon. The results of these observations are reported here and a comparison made with data obtained from material recovered from the watery stools of a patient with a villous papilloma of the rectum.

The first patient, a man aged 67 years, with a 20 -year history of symptoms typical of adult coeliac disease (confirmed by laboratory, $x$-ray studies, and peroral jejunal biopsy), made an excellent recovery following withdrawal of wheat gluten from his diet. Six months before admission to hospital he began to have attacks, lasting several days, of colicky abdominal pain and constipation during which he passed small quantities of thick mucus per rectum. Abnormal physical signs were absent except during a bout of constipation when abdominal distension and the passage of mucus per rectum were noted (Table I). Sigmoidoscopy revealed nothing abnormal apart from excessive mucus in the bowel but a barium enema showed considerable dilatation of the whole colon. Plasma electrolytes were normal; the urinary excretion of potassium was 54 and $42 \mathrm{mEq}$./ $24 \mathrm{hr}$. in collections made on two successive days. Estimates of faecal potassium were between 8 and 26 $\mathrm{mEq} . / 24 \mathrm{hr}$. over a period of six days when the bowel habit was normal. A tentative diagnosis of partial volvulus of the colon was made. At laparotomy the mesocolon was thickened and the grossly dilated sigmoid 

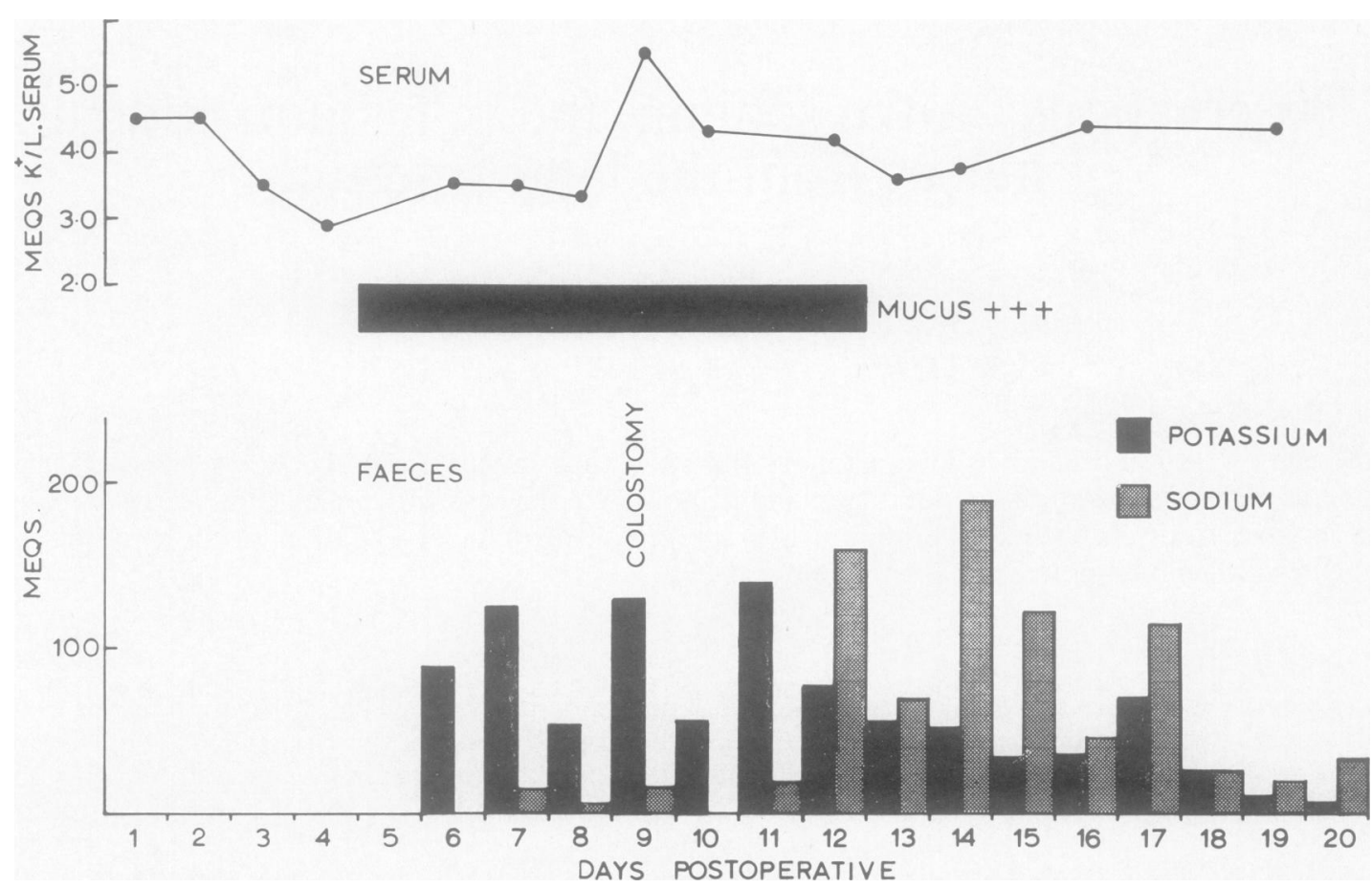

FIG. 1. The daily excretion of potassium and sodium, and the concentration of serum potassium of the first patient following colectomy.

colon was resected. Three days after operation, the patient was incontinent of about 1 to $1 \frac{1}{2}$ litres of mucus and the plasma concentration of potassium fell from 4.5 to $2.9 \mathrm{mEq}$. per litre (Fig. 1). A colostomy became necessary on the ninth postoperative day from breakdown of the suture line of the bowel anastomosis. From the sixth to the twelfth day the faeces and colostomy fluid contained excessive amounts of both mucus and potassium, the latter on three occasions exceeding 120 mEq. daily (Fig. 1). With the disappearance of mucus from the faeces, the potassium content decreased. The sigmoid colon removed at operation was normal apart from dilatation and slight flattening of the mucosa. There was no ulceration of the bowel wall. Histological examination showed a thick layer of mucin covering the surface of the mucosa and the mouths of the crypts. The goblet cells were distended with this material which stained strongly with mucicarmine and alcian blue but weakly with Hale's dialysed iron and P.A.S. There was no evidence of an inflammatory reaction.

Mucus was obtained from a second patient, a woman aged 56 years, with a villous papilloma situated at the rectosigmoid junction. For about six months before admission to hospital she complained of watery diarrhoea and a slimy rectal discharge. The daily volume of faecal fluid was between 350 and $680 \mathrm{ml}$. and over a four-day period the losses of sodium and potassium in the stools averaged 95 and $50 \mathrm{mEq}$. respectively per 24 hours. During this time the average daily outputs of sodium and potassium in the urine were low $(18$ and $15 \mathrm{mEq}$. respectively), but the plasma electrolyte concentrations and urea were within normal limits.

\section{CHEMICAL CONSTITUENTS OF THE MUCUS OBTAINED FROM THE FIRST PATIENT}

Specimens of jelly-like colonic mucus containing small opaque strands passed per rectum, free of faeces, blood, and cells, were immediately frozen at $-20^{\circ} \mathrm{C}$. until required. Varying proportions from different specimens of the mucus were found to be soluble in water, but attempts to isolate pure fractions were unsuccessful. Chemical investigations were therefore restricted to qualitative analyses of the crude material. Pooled specimens were brought to $p \mathrm{H} 7.4$ by the addition of hydrochloric acid and after being mixed in a blender, centrifuged to separate the opaque material. Electrolyte and non-protein constituents were removed by dialysis at $4^{\circ} \mathrm{C}$. for four days against frequent changes of distilled water, a small quantity of phenyl mercuric nitrate being added as preservative. The nitrogen content of the mucus before dialysis varied between 54 and $242 \mathrm{mg}$. per $100 \mathrm{ml}$. Pooled mucus after dialysis and drying contained $9,250 \mathrm{mg}$. of nitrogen per $100 \mathrm{~g}$. Paper electrophoresis of the crude mucus in barbiturate buffer $(p \mathrm{H} \mathrm{8.4)}$ showed no component with a mobility corresponding to a marker of human albumin, indicating no gross contamination with plasma protein. The polysaccharide fraction was split from the protein by stirring the mucus in $0.5 \mathrm{~N} \mathrm{NaCl}$ with an equal volume of chloroform (Shashoua and 
Kwart, 1959). Each fraction was then dialysed against distilled water for four days. After hydrolysis of the protein with $6 \mathrm{~N} \mathrm{HCl}$, the constituent amino-acids were identified by two-dimensional paper chromatography in phenol followed by a mixture of collidine and lutidine.

Considerable quantities of neutral and dicarboxylic but only small amounts of basic amino-acids were present. Glutamic and aspartic acids, glycine, serine, threonine, alanine, valine, leucine, and/or isoleucine gave large spots on the chromatograms after spraying with $0.1 \%$ ninhydrin in n-butanol. Those from cystine, phenylalanine, tyrosine, proline, and arginine were smaller. Histidine was identified in trace amounts, but lysine was not detected even after high loading of the papers. The polysaccharide fractions were hydrolysed and the neutral sugars separated from the amino sugars and identified by methods published by Atassi, Barker, and Stacey (1959). Large amounts of galactose and L-fucose were present, together with smaller amounts of mannose. Glucosamine and galactosamine were identified in about equal amounts by chromatography on Dowex 50 resin by the method of Gardell (1953). No sulphate could be detected in the polysaccharide fraction. The dialysed and dried mucus contained $5 \%$ of sialic acid determined by the method of Warren (1959). The constituents of the mucus were, therefore, similar to those reported for colonic mucus by Werner (1953) from a patient with a colostomy and by Johansen (1963) from a patient with fibrocystic disease of the pancreas.

\section{ELECTROLYTE COMPOSITION OF THE MUCUS}

Five specimens of mucus were obtained before and one specimen after operation (Table I). Determinations of $p \mathrm{H}$ and electrolyte analyses were made usually after thawing material preserved by freezing. On one occasion the $p \mathrm{H}$ was determined and an aliquot taken for analysis within a few minutes of the mucus being passed. The specimen was then kept frozen for several days and the measurements repeated after thawing. No change in the values was observed.
Table I shows that the $p \mathrm{H}$ of the mucus varied between 9.5 and 9.9 units, while the concentrations of both potassium and 'bicarbonate', which could be extracted with water, were between 128 and 200 and 87 and $155 \mathrm{mEq}$. per litre of mucus respectively. Both the potassium and 'bicarbonate' were readily removed by dialysing the mucus against distilled water (Table II) with a consequent fall of $p \mathrm{H}$. In

\section{TABLE II}

CONCENTRATION OF ELECTROLYTES EXTRACTABLE FROM 200 ML OF MUCUS BEFORE AND AFTER DIALYSIS AGAINST DISTILLED WATER AT $4^{\circ} \mathrm{C}$. FOR FOUR DAYS

\begin{tabular}{lcc}
$\begin{array}{l}\text { Electrolyte } \\
(m E q . / l .)\end{array}$ & Before Dialysis & After Dialysis \\
\hline $\mathrm{pH}$ & $9 \cdot 5$ & $7 \cdot 9$ \\
$\mathrm{~K}^{+}$ & 146 & 1 \\
$\mathrm{Na}^{+}$ & 3 & 4 \\
$\mathrm{Cl}^{-}$ & 33 & 20 \\
$\mathrm{HCO}_{3}{ }^{-}$ & 87 & 2
\end{tabular}

contrast the amounts of both sodium and chloride that could be extracted by this means were low. After extraction with water varying proportions of the mucus remained insoluble and it seemed likely that larger quantities of these two electrolytes were present and possibly more firmly bound to the mucus than could be demonstrated by extraction. Hydrolysis of several samples of the mucus showed that this was true for sodium. One sample from which were extracted $138 \mathrm{mEq}$. of potassium and only $3 \mathrm{mEq}$. of sodium per litre (a potassium/ sodium ratio of 46 to 1) was hydrolysed for 16 hours with $6 \mathrm{~N}$ hydrochloric acid. The potassium content of the hydrolysate was increased to $145 \mathrm{mEq}$. per litre and the sodium to $41 \mathrm{mEq}$. per litre giving a potassium/sodium ratio of 3.5 to 1 . The ease with which the potassium in the mucus could be replaced by sodium was demonstrated by incubating $5 \mathrm{ml}$. of undialysed material in $50 \mathrm{ml}$. of a solution simulating colonic fluid at $p \mathrm{H} 8$ containing $21 \mathrm{mEq}$, of potassium and 78, 48, and $51 \mathrm{mEq}$. of sodium.

TABLE I

THE $p H$ OF MUCUS AND CONCENTRATIONS OF EXTRACTABLE ELECTROLYTES ${ }^{1}$

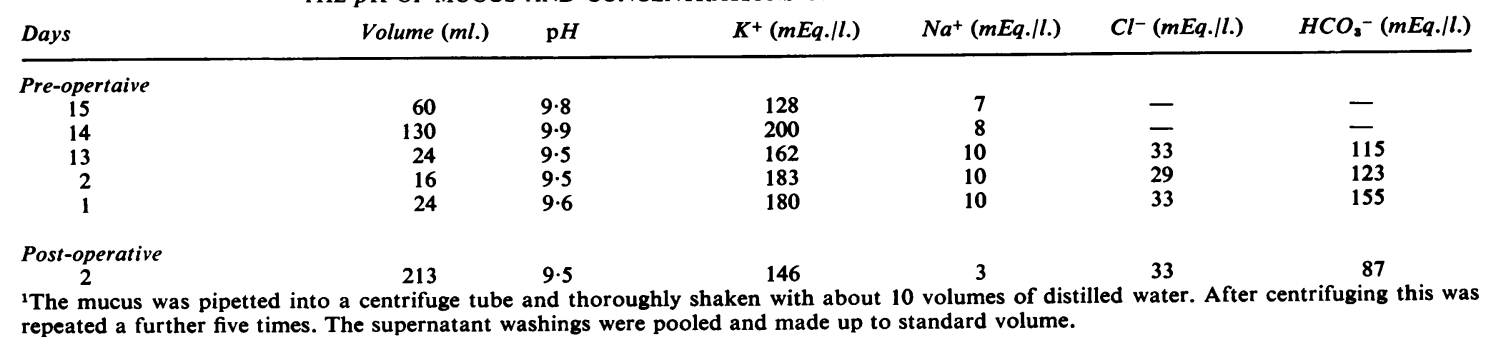


TABLE III

ELECTROLYTES OF SUPERNATANT RECTAL FLUID AND MUCUS FROM THE SECOND PATIENT

\begin{tabular}{|c|c|c|c|c|c|c|c|c|c|c|}
\hline \multirow[t]{3}{*}{ Time of Collection } & \multirow{3}{*}{$\begin{array}{l}\text { Interval } \\
(h r .)\end{array}$} & \multicolumn{6}{|c|}{ Supernatant Rectal Fluid } & \multicolumn{3}{|c|}{ Mucus } \\
\hline & & \multirow{2}{*}{$\begin{array}{l}\text { Volume } \\
\text { (ml.) }\end{array}$} & \multirow[t]{2}{*}{$\mathrm{p} H$} & \multicolumn{4}{|c|}{ Electrolytes (mEq.|ll.) } & \multirow{2}{*}{$\begin{array}{l}\text { Volume } \\
\text { (ml.) }\end{array}$} & \multicolumn{2}{|c|}{ Electrolytes (mEq./l.) } \\
\hline & & & & $\mathrm{Na}^{+}$ & $\boldsymbol{K}^{+}$ & $\mathrm{Cl}^{-}$ & $\mathrm{HCO}^{3-}$ & & $\mathrm{Na}^{+}$ & $K^{+}$ \\
\hline $\begin{array}{l}10.25 \text { a.m. } \\
2.00 \text { p.m. } \\
5.00 \text { p.m. } \\
6.00 \text { p.m }\end{array}$ & $\begin{array}{l}- \\
3 \cdot 6 \\
3 \cdot 0 \\
1 \cdot 0\end{array}$ & $\begin{array}{l}17 \cdot 5 \\
37 \cdot 0 \\
65 \cdot 0 \\
17 \cdot 5\end{array}$ & $\begin{array}{l}8 \cdot 65 \\
8.63 \\
9 \cdot 50 \\
8.95\end{array}$ & $\begin{array}{r}95 \\
111 \\
110 \\
121\end{array}$ & $\begin{array}{l}41 \\
53 \\
57 \\
68\end{array}$ & $\begin{array}{l}- \\
\overline{120} \\
155\end{array}$ & $\begin{array}{l}- \\
\overline{27} \\
28\end{array}$ & $\begin{array}{r}0.5 \\
1.0 \\
15.0 \\
3.0\end{array}$ & $\begin{array}{l}- \\
\overline{112} \\
146\end{array}$ & $\begin{array}{l}- \\
53 \\
64\end{array}$ \\
\hline
\end{tabular}

chloride, and bicarbonate respectively, concentrations found by Randall (1952) in colonic fluid. The potassium/sodium ratio of 3.5 to 1 in hydrolysed mucus was reversed after incubation for 60 minutes at $37^{\circ} \mathrm{C}$. and was found to be 1.1 to 3 and was thus similar to the ratio of these ions in the suspending fluid. By contrast, in specimens of inspissated mucus removed from the sigmoid colon at operation and hydrolysed with $6 \mathrm{~N}$ hydrochloric acid for six hours, negligible amounts of potassium and sodium ( 3 and $2 \mathrm{mEq}$. respectively per $\mathrm{g}$. of nitrogen) were found. These values correspond to about 7 and $5 \mathrm{mEq}$. of potassium and sodium per litre of hydrated mucus.

\section{ELECTROLYTE CONTENT OF RECTAL}

FLUID AND MUCUS FROM THE SECOND PATIENT

Rectal discharges from the second patient were collected over a period of eight hours, and insoluble mucus separated by centrifuging. Electrolyte analyses and $p \mathrm{H}$ measurements were carried out on the supernatant liquid of each sample and the sodium and potassium content of two specimens of the insoluble mucus determined after hydrolysis with hydrochloric acid.

The results of the analyses are shown in Table III.

The sodium and potassium content of the alkaline supernatant rectal fluid was similar to values reported by others. The concentration of both electrolytes showed a progressive increase during the latter period of the study, due probably to the differential absorption of water by the colon. The highest $p \mathrm{H}$ was observed in the third sample containing the greatest proportion of insoluble mucus. In the last two samples, concentrations of sodium and potassium were similar in both the supernatant fluid and the insoluble mucus. This finding was expected in view of the alterations in the electrolyte composition of mucus in the first study which could be brought about by dialysis against distilled water (Table II), and by incubation in a solution of different ionic composition. Two hundred millilitres of centrifuged rectal fluid after dialysis and freeze drying yielded $61 \mathrm{mg}$. of protein, giving a strongly positive reaction for carbohydrate with Molisch's reagent. If it is assumed that all the potassium in each sample less $5 \mathrm{mEq}$. $/ 1$. was derived from the mucus alone and that about half of the mucus secreted by the tumour was soluble in the supernatant fluid then the concentrations of potassium present initially in the mucus approximated to 150 and $230 \mathrm{mEq}$. per litre, values which are similar to those recorded in Table $I$.

These results give some support to the view that mucus from the large intestine may contain high concentrations of potassium and demonstrate the ease with which this electrolyte may be removed. They also offer a tentative explanation for the wide variations in the potassium content which have been observed by a number of investigators in the rectal discharges of patients with villous tumours and in the samples of colonic fluid obtained at operation (Duthie and Atwell, 1963). Further studies are necessary to establish that mucus from the large intestine of normal subjects contains potassium in concentrations similar to those reported here. If this proves to be the case the process of inspissation which releases electrolytes might be one of the important mechanisms whereby potassium is conserved and its excretion in the faeces is reduced and maintained at about $10 \mathrm{mEq}$. per day. Any intestinal condition which prevents adequate degradation or inspissation of mucus will therefore favour potassium depletion.

One practical aspect of reporting these findings is to draw attention to the likelihood of acute electrolyte depletion, especially of potassium, when large quantities of mucus are excreted. Observations of alterations in the nature of the stools in patients with villous tumours, chronic obstruction of the large bowel, ulcerative colitis, and steatorrhoea are therefore of significance in treatment as they may indicate urgent replacement of potassium.

I wish to acknowledge the support of Professor W. M. Arnott of the Department of Medicine, University of Birmingham, and financial help from the Medical Research Council, London, and the Endowment Research Fund of the United Birmingham Hospitals. I am also grateful to Mr. R. K. Debenham, F.R.C.S., and 
Mr. V. S. Brookes, F.R.C.S., consultant surgeons to the Queen Elizabeth Hospital, Birmingham, for allowing me to investigate their patients, and to Dr. T. Whitehead, consultant biochemist to the Queen Elizabeth Hospital, and his staff for the many electrolyte analyses which were carried out. This investigation was part of a programme aided by the United States Army European Office of Research under Contract No. DA-91-591-EUC-2046, to which acknowledgements and thanks are due.

\section{REFERENCES}

Atassi, M. Z., Barker, S. A., and Stacey, M. (1959). Neuraminic acid and its relation to chronic bronchitis. III. Carbohydrate constituents of sputum. Clin. chim. Acta, 4, 823-827.

Cooling, C., and Marrack, D. (1957). Potassium-secreting tumour of the colon. Proc, roy. Soc. Med., 50, 272-274.

Duthie, H. L., and Atwell, J. D. (1963). The absorption of water, sodium, and potassium in the large intestine with particular reference to the effects of villous papillomas. Gut, 4, 373-377.

Gardell, S. (1953). Separation on Dowex 50 ion exchange resin of glucosamine and galactosamine and their quantitative determination. Acta chem. scand., 7, 207-215.
Johansen, P. G. (1963). Physiochemical investigations on two unusual sialic acid-rich mucoids from the intestinal tract of patients with fibrocystic disease of the pancreas. Biochem. J., 87, 63-70.

Little, J. M. (1964). Potassium imbalance and rectosigmoid neoplasia. Lancet, 1, 302-303.

Lubran, M., and McAllan, P. M. (1951). Potassium deficiency in idiopathic steatorrhoea. Ibid., 1, 321-322.

Posey, E. L., and Bargen, J. A. (1950). Metabolic derangements in chronic ulcerative colitis. Gastroenterology, 16, 39-50.

Randall, H. T. (1952). Water and electrolyte balance in surgery. Surg. Clin. N. Amer., 32, 445-469.

Rowe, P. B. (1964). A mucus-secreting villous adenoma of the rectum. Gut, 5, 250-252.

Roy, A. D., and Ellis, H. (1959). Potassium-secreting tumours of the large intestine. Lancet, 1, 759-760.

Shashoua, V. E., and Kwart, H. (1959). The structure and constitution of mucus substances. II. The chemical constitution of Busycon mucus. J. Amer. chem. Soc., 81, 2899-2905.

Shnitka, T. K., Friedman, M. H. W., Kidd, E. G., and MacKenzie, W. C. (1961). Villous tumours of the rectum and colon characterized by severe fluid and electrolyte loss. Surg. Gynec. Obstet., 112, 609-621.

Southwood, W. F. W. (1962). Villous tumours of the large intestine: their pathogenesis, symptomatology, diagnosis and management. Ann. roy. Coll. Surg. Engl, , 30, 23-45.

Warren, L. (1959). The thiobarbituric acid assay of sialic acids. J. biol. Chem., 234, 1971-1975.

Werner, I. (1953). Studies on glycoproteins from mucous epithelium and epithelial secretions. Acta Soc. Med. upsalien, 58, 1-55. 